\title{
Preparation and Characterization of High-Temperature Thermally Stable Alumina Composite Membrane
}

\author{
Yue-Sheng Lin and Anthonie J. Burggraaf \\ Laboratory of Inorganic Chemistry, Materials Science, and Catalysis, \\ Department of Chemical Technology, University of Twente, 7500 AE Enschede, Netherlands
}

A crack- and pinhole-free composite membrane consisting of an $\alpha$-alumina support and a modified $\boldsymbol{\gamma}$-alumina top layer which is thermally stable up to $1100^{\circ} \mathrm{C}$ was prepared by the sol-gel method. The supported thermally stable top layer was made by dipcoating the support with a boehmite sol doped with lanthanum nitrate. The temperature effects on the microstructure of the (supported and unsupported) La-doped top layers were compared with those of a common $\gamma$-alumina membrane (without doping with lanthanum), using the gas permeability and nitrogen adsorption porosimetry data. After sintering at $1100^{\circ} \mathrm{C}$ for $30 \mathrm{~h}$, the average pore diameter of the La-doped alumina top layer was $17 \mathrm{~nm}$, compared to $109 \mathrm{~nm}$ for the common alumina top layer. Addition of poly(vinyl alcohol) to the colloid boehmite precursor solution prevented formation of defects in the $\boldsymbol{\gamma}$ alumina top layer. After sintering at temperatures higher than $900^{\circ} \mathrm{C}$, the common alumina top layer with addition of poly(vinyl alcohol) exhibits a bimodal pore distribution. The La-doped alumina top layer (also with addition of poly(vinyl alcohol)) retains a monopore distribution after sintering at $1200^{\circ} \mathrm{C}$. [Key words: alumina, membrane, sol-gel, thermal properties, high temperature.]

\section{Introduction}

C ERAMIC membranes are technically important in separation and filtration as well as in catalytic reactions, because of some unique characteristics in comparison with polymeric membranes. They have high thermal and chemical stability, long life and good defouling properties in application, and they can have catalytic properties. The potential application of the ceramic membranes at elevated temperatures requires the study and even further improvement of the ceramic membrane thermal stability. Of the various methods used for inorganic membrane preparation, the sol-gel approach $^{1-3}$ is considered to be the most practical one for ceramic membrane synthesis because of its ability to make microscale thin membrane top layers of nanoscale pore diameter with narrow pore-size distribution. For the ceramic membrane top layers prepared by the sol-gel approach, the smallest possible pore size is determined by the primary particle size in the sol (colloid suspension). ${ }^{4}$ This smallest pore size is formed by drying and calcining the gel at a relatively low temperature. In most cases the pore size of a membrane top layer increases with the firing temperature. The pore growth with temperature has been confirmed in top layers of

T. O. Mason - contributing editor

Manuscript No. 197594. Received April 27, 1990; approved September 11 1990.

Supported by the Dutch Ministry of Economical Affairs vnder grant: IOP Technical Ceramics No. 87 A045.
$\gamma-\mathrm{Al}_{2} \mathrm{O}_{3}, \mathrm{TiO}_{2}$, and $\mathrm{ZrO}_{2}{ }^{3,5,6}$ Consequently, it is difficult to keep the pore diameter of a ceramic membrane top layer smaller than $50 \mathrm{~nm}$ at firing temperatures higher than $1000^{\circ} \mathrm{C}$.

In the limited studies related to the thermal stability of ceramic membranes, Burggraaf and Keizer and their coworkers ${ }^{2,4,6,7}$ determined the pore size of some ceramic membrane top layers for different sintering temperatures. They reported that the pore size of the $\gamma$-alumina top layers increases significantly at temperatures between $900^{\circ}$ and $1000^{\circ} \mathrm{C}$. Without indicating the sintering time, a set of data of pore size vs sintering temperature $\left(500^{\circ}\right.$ to $\left.1000^{\circ} \mathrm{C}\right)$ for a $\gamma$ alumina top layer has been reported by $\operatorname{Cot}$ and his coworkers in several publications. ${ }^{3,9}$ These published papers, however, have mainly dealt with synthesis of the ceramic membranes and their characterization rather than with their thermal stability. In a study on the calcination and the thermal stability of alumina ceramic membrane, Van Veen et al. ${ }^{10}$ recently investigated the pore structure (surface area, pore size, and pore volume) of the sol-gel-prepared $\gamma-\mathrm{Al}_{2} \mathrm{O}_{3}$ membrane top layers as a function of calcination or sintering temperature in a relatively low temperature range $\left(425^{\circ}\right.$ to $600^{\circ} \mathrm{C}$ ). The increase in the pore diameter of the studied membrane top layers was less than $1 \mathrm{~nm}$ after $800 \mathrm{~h}$ calcination or sintering in the temperature range mentioned.

As part of the program for preparing high-temperature thermally stable ceramic membranes to be used as substrates for CVD membrane modification, ${ }^{11}$ Lin $e t$ al. ${ }^{12}$ recently studied in a more systematic way the thermal stability of the sol-gel-prepared alumina membrane top layers and the improvement of the microstructural thermal stability of these membrane top layers. The thermal stability of four different kinds of unsupported alumina membrane top layers was studied in a rather large temperature range $\left(450^{\circ}\right.$ to $\left.1200^{\circ} \mathrm{C}\right)$. It was found in that study ${ }^{12}$ that the average pore size of the pure alumina membranes and the poly(vinyl alcohol) (PVA) doped membranes increases sharply after sintering at temperatures higher than $1000^{\circ} \mathrm{C}$. Addition of $3 \% \mathrm{La}$ (cation percentage), either by mixing lanthanum nitrate in the alumina sol or impregnating lanthanum nitrate into calcined alumina gel followed by a second heat treatment, can considerably stabilize the pore structure of the alumina membrane top layers. The pore diameter for the La-doped membranes is stabilized around $25 \mathrm{~nm}$ after sintering at $1200^{\circ} \mathrm{C}$ for $30 \mathrm{~h}$, about onesixth of that for the pure alumina membranes sintered under the same conditions. The substantial increase in the pore size for the pure alumina membranes at sintering temperatures of $1000^{\circ}$ to $1200^{\circ} \mathrm{C}$ is accompanied by the phase transformation from $\gamma$-alumina via transition alumina to $\alpha$-alumina. No composite membranes with the thermal-stability-improved top layer were reported in that paper.

The main objective of the present paper is to report the preparation and characterization of crack- and pinhole-free composite alumina membranes with improved thermally stable alumina top layers. Emphasis is given to the comparison of the temperature dependency of the pore structure between a common alumina membrane and the membrane with improved thermal stability. 


\section{Experimental Procedure}

\section{(1) Membrane Preparation and Sintering Experiments}

The pure boehmite sol ( $1 M$ boehmite) was prepared by adding alumina secondary butoxide* to water and peptizing the solution with nitric acid $\left(\mathrm{HNO}_{3}(\mathrm{~mol}) /\right.$ alkoxide $(\mathrm{mol})=$ $0.07)$ in the procedure described by Leenaars et al. ${ }^{6} \mathrm{~A}$ small amount of lanthanum nitrate solution $(0.3 M, \mathrm{pH} 1)$ was mixed with the pure boehmite sol to form the La-doped boehmite sol (molar ratio of $\mathrm{La}\left(\mathrm{NO}_{3}\right)_{3}$ to $\gamma$-AlOOH is 0.03 ). The $\mathrm{La}-$ doped sol was shaken thoroughly to give a homogeneous mixture. A solution of $\mathrm{PVA}^{\dagger}$ (mol wt $=72000$ ) was prepared by adding $3.5 \mathrm{~g}$ of PVA to $100 \mathrm{~mL}$ of $0.05 M \mathrm{HNO}_{3}$ solution. The PVA solution was then mixed with the pure boehmite solution and the La-doped boehmite solution (ratio of the volume of PVA solution to that of boehmite solution is $2: 3$ ) to form a PVA-doped boehmite sol and a PVA + La-doped boehmite sol, which were used to make the common alumina top layer and the alumina top layer with improved thermal stability, respectively. Unsupported membrane top layers were prepared by drying the two final sols in petri dishes at room temperature as described by Lin et al. ${ }^{12}$

The $\alpha$-alumina support disks (disk size $40 \mathrm{~mm} \times 2 \mathrm{~mm}$ ) had a porosity of 0.5 and an average pore diameter of $0.2 \mu \mathrm{m}$. Before being dipcoated with a sol, the support disks were polished with sandpaper, followed by cleaning in an ultrasonic acetone bath. Afterwards the supported disks were fired at $1150^{\circ} \mathrm{C}$ for more than $30 \mathrm{~h}$ to ensure a good thermal stability of the support pore structure. This pretreatment of the support disks was important for the accurate measurement of the permeability for a supported top layer.

The common membrane composite (referred here as membrane $A$ ) and the membrane composite with improved thermal stability (membrane B) were prepared by dipcoating the support disks with the PVA-doped boehmite sol and the La + PVA-doped boehmite sol, respectively. During preparation, one side of a porous support disk was brought into contact with a proper sol for a short time ( 3 to $5 \mathrm{~s}$ ). A capillary pressure was created which forced the dispersion medium to flow into the dry part of the support. A gel layer was formed at the entrance of the support because of the concentration of the sol particles during the dipping process. The supported gel was dried at $40^{\circ} \mathrm{C}$ in air with a controlled humidity, followed by an extended period of careful calcination at $450^{\circ} \mathrm{C}$.

A La-impregnated alumina membrane (membrane $\mathrm{C}$ ) was also prepared by the wet-impregnation method to investigate the feasibility of making the thermally stable membrane by the more conventional doping method. This was done by immersing a calcined alumina membrane composite (membrane A) into $10 \mathrm{~mL}$ of the $0.3 \mathrm{M}$ lanthanum nitrate solution. The membrane disk with the nitrate solution was dried in air at room temperature, followed with a second period of calcination at $450^{\circ} \mathrm{C}$. Although the moles of $\mathrm{La}\left(\mathrm{NO}_{3}\right)_{3}$ in the nitrate solution used for each impregnation was roughly the same as the moles of $\mathrm{Al}_{2} \mathrm{O}_{3}$ in a supported top layer, most of the lanthanum nitrate in each impregnation was believed to be impregnated on the support, because the support volume was about 500 times larger than the top layer in the membrane composite. In this preliminary study, no effort was made to impregnate a controlled amount of La on the top layer.

To study the thermal stability of the membrane top layers, supported and unsupported top layers (membrane composites) after calcining at $450^{\circ} \mathrm{C}$ were fired at different temperatures $\left(900^{\circ}\right.$ to $\left.1200^{\circ} \mathrm{C}\right)$ for about $30 \mathrm{~h}$ in temperaturecalibrated furnaces. In all sintering experiments, the furnaces were heated up at a rate of $90^{\circ} \mathrm{C} / \mathrm{h}$ to reach a given sintering temperature and cooled down at the same rate to room temperature after sintering at a high temperature.

\section{(2) Characterization}

The extent of visible cracking of the supported top layers was examined by a microscope, and each top layer without visible cracks was further tested by a gas permeation technique. ${ }^{13}$ In the gas permeation measurements, helium permeability was measured at different average pressures for a support (before dipcoating) and for a support/top layer composite based on the same support respectively at room temperature, using a homemade permeation apparatus. The permeability through the supported top layers was then calculated from the permeabilities of the support and the support/ top-layer composite by the following method.

For a homogeneous porous disk and pure nonadsorbable gas, the gas permeability $F$ can be correlated to the average pressure across the disk $\left(P_{\text {av }}\right)$ by

$$
F / L=\alpha+\beta P_{\mathrm{av}}
$$

where the permeability is defined as $F=Q L / S\left(P_{\mathrm{h}}-P_{1}\right)$ with $Q$ being the volumetrical gas flow rate, $L$ the disk thickness, $S$ the permeation area of the disk, and $P_{\mathrm{h}}$ and $P_{1}$ the pressure at high-pressure side and low-pressure side of the disk. The permeability coefficients $\alpha$ and $\beta$ are attributed to Knudsen and viscous flows, respectively, as

$$
\begin{aligned}
\alpha & =1.06(1 / L)(\varepsilon / \tau) r(R T M)^{-1 / 2} \\
\beta & =0.125(1 / L)(\varepsilon / \tau) r^{2} / \mu R T
\end{aligned}
$$

where $\varepsilon$ and $\tau$ are the porosity and tortuosity factor, respectively; $r$ is the average pore radius; $T$ is the temperature; $M$ and $\mu$ are the molecular weight and viscosity of the permeating gas, respectively; and $R$ is the gas constant. The coefficients $\alpha$ and $\beta$ for a support can be found from the experimentally measured permeability-average pressure data for the support.

For measuring the permeability through a supported top layer, a helium flow at a given flow rate $Q$ was passed, from the top layer side, through the support/top-layer composite membrane. After the equilibrium was reached, a high pressure in the top-layer side (upstream side, $P_{\mathrm{h}}$ ) and a low pressure in the support side (downstream side, $P_{1}$ ) were measured by pressure meters. The pressure at the interface of the top layer and support in the composite membrane $\left(\boldsymbol{P}_{\mathrm{m}}\right)$ at this flow rate was then calculated by the following equation derived from the series model: ${ }^{14}$

$$
\begin{aligned}
P_{\mathrm{m}}= & {\left[\left(\alpha_{\mathrm{s}} / \beta_{\mathrm{s}}\right)^{2}+2 P_{1}\left(\alpha_{\mathrm{s}} / \beta_{\mathrm{s}}\right)+P_{1}^{2}+2 Q / \alpha_{\mathrm{s}} S\right]^{1 / 2} } \\
& -\alpha_{\mathrm{s}} / \beta_{\mathrm{s}}
\end{aligned}
$$

where permeation coefficients $\alpha_{\mathrm{s}}$ and $\beta_{\mathrm{s}}$ were calculated from the permeability data of the support only. Thus, a permeability value for the supported top layer at the average pressure of $P_{\mathrm{av}}=\left(P_{\mathrm{h}}+P_{\mathrm{m}}\right) / 2$ was obtained using the defining equation

$$
(F / L) \text { (top layer })=Q / S\left(P_{\mathrm{h}}-P_{\mathrm{m}}\right)
$$

After the permeability data for a supported top layer at different average pressures were obtained, the crack-free supported top layer was examined by the pressure independency of the helium permeability through the supported top layer.

The pore size distribution, average pore size, pore volume, and surface area (BET) for the unsupported top layers were determined by a nitrogen adsorption and desorption porosimeter $^{\ddagger}$ (for samples with a pore diameter smaller than $20 \mathrm{~nm}$ ) and a mercury porosimeter ${ }^{\S}$ (for samples with a pore diameter larger than $20 \mathrm{~nm}$ ). The nitrogen desorption isotherms were used to calculate the pore size distribution and the average pore size. The pore size data for the supported top layers were obtained from the gas permeation data (the coefficients $\alpha$, see Eq. (2)). 


\section{Results and Discussion}

As found in the previous study, ${ }^{12}$ the addition of PVA to a boehmite sol reduces the thermal stability of the alumina membranes at high temperatures. So the first attempt was to prepare PVA-free supported La-doped alumina top layers. The supported La-doped top layers were seriously cracked (visible with the microscope) without addition of PVA. Furthermore, the extent of the cracking increased with the aging time (time lag between the moment of mixing lanthanum nitrate into boehmite sol and the moment of dipcoating) and bochmite concentration. This is probably due to the thixotropic properties of the La-doped boehmite sol of which the viscosity varies with aging time and boehmite concentration. Consequently, PVA was also added to the La-doped boehmite sol as a surface additive to reduce the stress in the top layer and at the interface between the top layer and support during the drying process. Supported La-doped top layers made by dipcoating the PVA + La-doped boehmite sol (with half-hour aging time and $0.5 M$ boehmite concentration) or by impregnating lanthanum nitrate into a supported alumina top layers (prepared from the PVA-doped boehmite sol) were crack free as observed with the microscope. Figure 1 is a SEM photo showing a cross section of a composite membrane with a La-doped top layer. The thickness of the supported top layer estimated from the SEM photo is about $5 \mu \mathrm{m}$.

The supported top layers were further examined by helium permeability data at different average pressures. Three sets of permeability data were measured for one composite membrane: the first one for the support before dipcoating with sol, the second one for the support/top-layer membrane after calcination at $450^{\circ} \mathrm{C}$ but before further sintering at a higher temperature, and the third one for the same support/top-layer membrane but after sintering at a higher temperature $\left(1000^{\circ}\right.$ or $1100^{\circ} \mathrm{C}$ ) for $30 \mathrm{~h}$. The permeability data at different average pressures were then calculated from the sets of permeability data for the supported top layer before or after sintering at a higher temperature. To give an example, Figs. 2 and 3 show the permeability data for one composite membrane with a La-doped alumina top layer before (Fig. 2) and after (Fig. 3) sintering at $1100^{\circ} \mathrm{C}$ for $30 \mathrm{~h}$. The permeability data at different average pressures can be well fitted with Eq. (1). Both sets of permeability data for the supported top layer before and after sintering are independent of the average pressure (i.e., coefficient $\beta=0$ ), indicating no viscous flow in the supported top layer. So the supported top layer is shown to be crack free and pinhole free. The permeability for such a crack-free top layer is contributed solely by the Knudsen

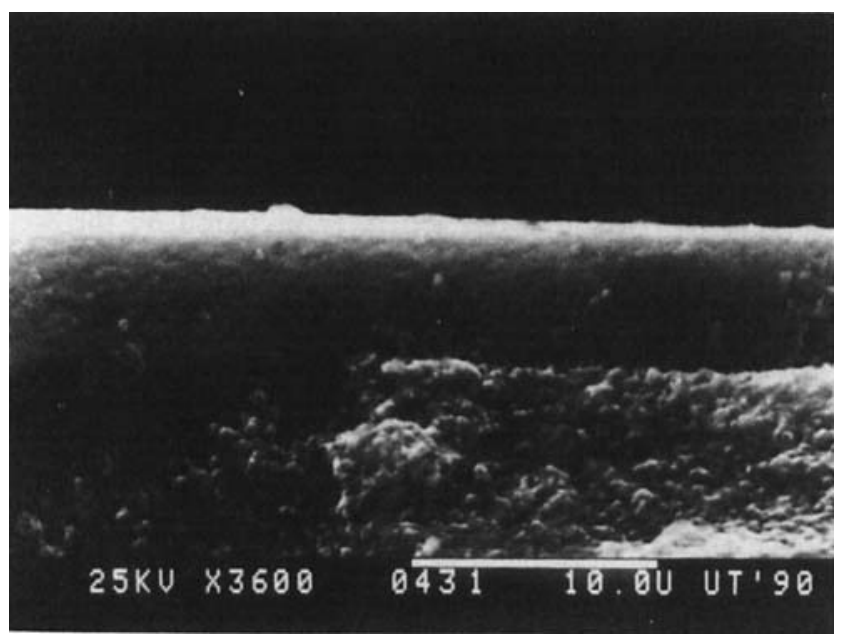

Fig. 1. SEM photo of the composite membrane with La-doped alumina top layer (membrane B with $3 \% \mathrm{La}$ ).

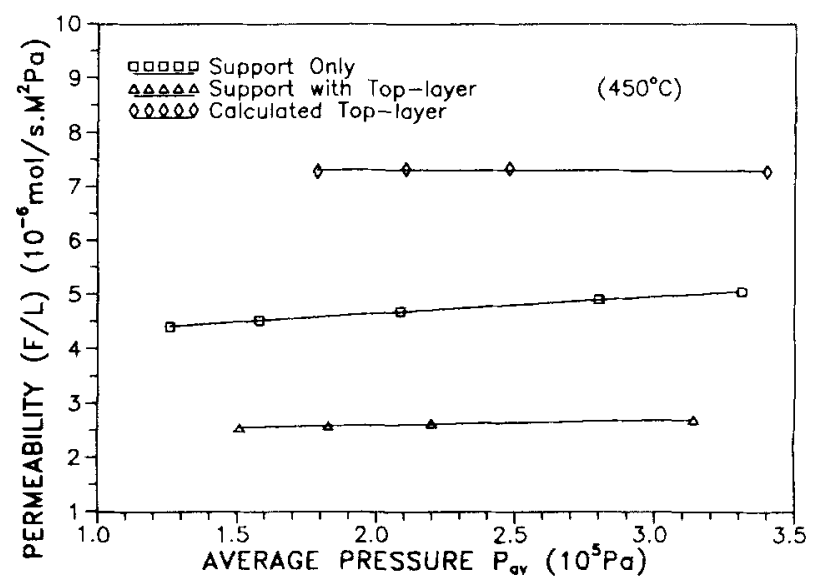

Fig. 2. Gas permeability for a composite membrane before sintering at a higher temperature.

flow, i.e., $F / L=\alpha$. It should be pointed out that without further pretreatment the pore size of the alumina support disks prepared using the supplier-suggested preparation procedure increased by about $14 \%$ after firing at $1100^{\circ} \mathrm{C}$ for $30 \mathrm{~h}$. This instability of the support would certainly affect seriously the accuracy of the calculation of the permeability for the supported top layer after sintering at $1100^{\circ} \mathrm{C}$ (or even make the calculation impossible). The careful further pretreatment of the support disks as mentioned in the previous section substantially stabilized the support and minimized the further pore growth, after sintering at temperatures lower than $1150^{\circ} \mathrm{C}$ for $30 \mathrm{~h}$, to a negligible level.

The values of the permeability coefficient $\alpha$ for the supported top layers of the three types of membranes $(A, B$, and $C$ ) are given in Table I (note that the coefficient $\beta=0$ ). The three samples for sintering at $1000^{\circ} \mathrm{C}$ were prepared with a longer contacting time (about $5 \mathrm{~s}$ ) during dipcoating, which gives a thicker top layer, while a shorter contacting time (about $3 \mathrm{~s}$ ) was used for the three samples for sintering at $1100^{\circ} \mathrm{C}$. The difference in the values of coefficient $\alpha$ between these two groups of samples before sintering is certainly due to the difference in the top-layer thickness. In the same group of samples, the coefficient $\alpha$ (before sintering) for the membrane type B (prepared from PVA + La-doped boehmite sol) is smaller than that for membranes $A$ and $C$ (prepared from the PVA-doped sol). As the pore structure for these three types of membrane top layers before sintering is similar (see further discussion below), the smaller value of coefficient $\alpha$ for membrane B indicates a thicker top layer formed from the PVA + La-doped sol. This results from the

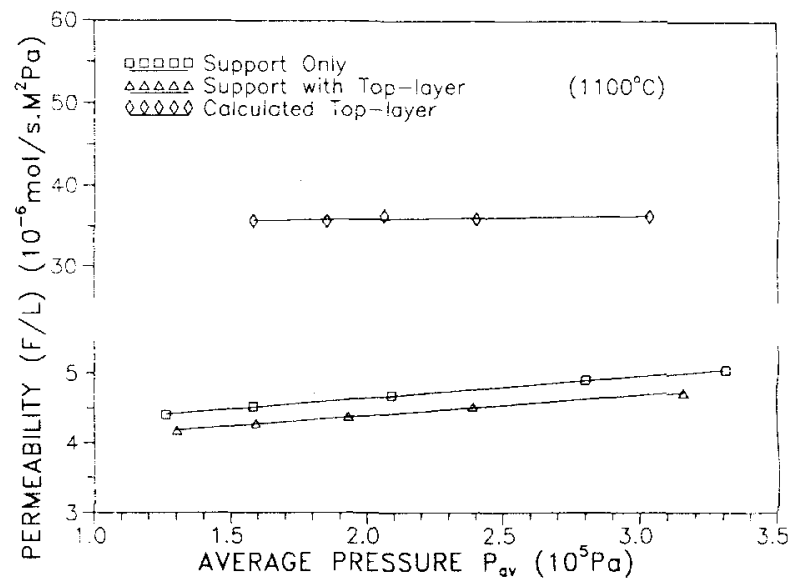

Fig. 3. Gas permeability for the same composite membrane as shown in Fig. 2 after sintering at $1100^{\circ} \mathrm{C}$ for $30 \mathrm{~h}$. 
Table I. Experimental Values of the Permeability Coefficient $\alpha$ and the Ratio $R$ for the Supported Top Layers Measured with He at Room Temperature

\begin{tabular}{|c|c|c|c|c|c|c|}
\hline \multirow[b]{3}{*}{ Membrane type } & \multicolumn{3}{|c|}{ Sintering at $10010^{\circ} \mathrm{C}$} & \multicolumn{3}{|c|}{ Sintering at $1100^{\circ} \mathrm{C}$} \\
\hline & \multicolumn{2}{|c|}{$\left(\times 10^{-6} \mathrm{~mol} /\left(\mathrm{s} \cdot \mathrm{m}^{2} \cdot \mathrm{Pa}\right)\right)$} & \multirow[b]{2}{*}{ Ratio $R^{*}$} & \multicolumn{2}{|c|}{$\left(\times 10^{-6} \mathrm{~mol} /\left(\mathrm{s} \cdot \mathrm{m}^{2} \cdot \mathrm{Pa}\right)\right)$} & \multirow[b]{2}{*}{ Ratio $R^{*}$} \\
\hline & Before & After & & Before & After & \\
\hline A (with PVA) & 4.16 & 17.7 & $4.3(4.3)$ & 6.82 & $>300$ & $>40(>35)$ \\
\hline B (PVA + doped La) & 2.44 & 5.28 & $2.2(3.1)$ & 5.39 & 24.7 & $4.6(5.8)$ \\
\hline C (PVA + impr. La) & 5.16 & 15.8 & 3.1 & 7.26 & 35.7 & 3.9 \\
\hline
\end{tabular}

higher viscosity for the La-doped sol. A further discussion on $\alpha$ values is given below.

The pore size distribution, average pore size, BET surface area, and pore volume of the unsupported PVA + La-doped top layers and PVA-doped top layers at different sintering temperatures (for $30 \mathrm{~h}$ ) were measured by the porosimetry method (Table II). A comparison of the pore size growth as a function of sintering temperature with constant sintering time $(30 \mathrm{~h})$ between the PVA + La-doped top layer and the PVAdoped top layer is given in Fig. 4, which shows an increase in the thermal stability for the La-doped top layer by about $100^{\circ} \mathrm{C}$. The pore diameter of the La-doped top layer is about $17 \mathrm{~nm}$ after sintering at $1100^{\circ} \mathrm{C}$ for $30 \mathrm{~h}$, while the pore diameter for the non-La-doped top layer is about 7 times larger than that of the La-doped top layer.

Another important improvement in the thermal stability for the La-doped top layer is in the pore size distribution. Figure 5 shows the pore size distributions for the PVA + Ladoped top layer and PVA-doped top layer after sintering at $1000^{\circ} \mathrm{C}$ for $30 \mathrm{~h}$. As evidenced in Fig. 5 (see the solid curve), the pore size distribution for the non-La-doped top layer exhibits a larger average pore size as well as a bimodal pore size distribution. This bimodal pore size distribution for the nonLa-doped top layer becomes more significant after sintering at the higher temperatures. Figure 6 shows the average pore diameters for the two groups of pores for the non-La-doped top layer as a function of sintering temperature $(30-\mathrm{h}$ sintering time). The average pore diameter of the group of the larger pores increases more extensively than that of the smaller pores. Furthermore, the volume percentage of the larger pores increases from $0 \%$ after sintering at $900^{\circ}$ for $30 \mathrm{~h}$ to $4 \%, 38 \%$, and $45 \%$ after sintering at $1000^{\circ}, 1100^{\circ}, 1200^{\circ} \mathrm{C}$, respectively, for $30 \mathrm{~h}$. The growth of the larger pores is mainly responsible for the average pore size increase of the non-La-doped top layer at the high sintering temperatures. The mechanism for such a bimodal distribution and the growth of the two groups of pores of different size for the non-La-doped top layer is not quite clear and requires further study. Nevertheless, it is important to note that such a bimodal distribution was not found for the PVA + La-doped top layer even after sintering at $1200^{\circ} \mathrm{C}$ for $30 \mathrm{~h}$.

The pore volume changes with sintering temperature $(30-\mathrm{h}$ sintering time) for both the PVA + La-doped and PVAdoped top layers are less significant, as seen in Fig. 7. This indicates a small change in the porosity after sintering at different temperatures. For example, the porosity calculated from the pore volume data for the La-doped top layer varies from 0.51 after calcination at $450^{\circ} \mathrm{C}$ to 0.41 after sintering at $1200^{\circ} \mathrm{C}$ for $30 \mathrm{~h}$. The BET surface area for both top layers decreased approximately linearly with sintering temperature. Similar findings were reported and discussed in more detail in the previous study for other sol-gel-prepared alumina top layers. ${ }^{12}$ This kind of BET surface area-sintering temperature relation was also found in other studies for alumina catalyst supports. ${ }^{15-18}$

As reported above, the effects of sintering temperature on the porosity of the top layers are much smaller than the effects on the pore size, and consequently the thickness for a supported top layer should be essentially the same before and after sintering at a higher temperature. So the ratio $R$ of the pore size for a supported top layer after sintering at a higher temperature to that of the same supported top layer before sintering can be approximately calculated from the permeability coefficient $\alpha$ by the following relation (with reference to Eq. (2)):

$$
R=\frac{r(\text { after sintering })}{r(\text { before sintering })} \approx \frac{\alpha(\text { after sintering })}{\alpha \text { (before sintering })}
$$

Values of $R$ for the supported top layers measured by the gas permeability method and for the unsupported top layers of the same type measured by the porosimetry method (using nitrogen desorption isotherms) are also listed in Table I. If one considers that some variation on the porosity and tortuosity due to sintering may affect the permeability data, the values of $R$ measured by the permeability method are in remarkably good agreement with those measured by the porosimetry method. This indicates that the two methods may be equivalent for the characterization of such fine pore membrane top layers. The values of $R$ for membranes $\mathrm{B}$ and $\mathrm{C}$ are smaller than those for membrane $A$, and after sintering at $1100^{\circ} \mathrm{C}$ this difference becomes more significant. These data further show the improvement on the thermal stability for the La-doped alumina membranes (B and $C$ ).

Comparing the values of $R$ for the two La-doped membranes (B and $C$ ) prepared by the two different doping methods, the wet-impregnation method (membrane $C$ ) gives larger values of $R$ than the method of doping $\mathrm{La}$ into the boehmite sol (direct doping method), as seen in Table I for the supported top layers. This may be due to the fact that the La content in the supported top layer prepared by the wetimpregnation method is possibly smaller than that achieved

Table II. Average Pore Diameter, BET Surface Area, and Pore Volume of Unsupported Top Layers After Sintering at Different Temperatures for $30 \mathrm{~h}$

\begin{tabular}{cccccccc}
\hline \multirow{2}{*}{$\begin{array}{c}\text { Firing } \\
\text { temp }\left({ }^{\circ} \mathrm{C}\right)\end{array}$} & $d(\mathrm{~nm})$ & $\begin{array}{c}S_{\mathrm{BET}} \\
\left(\mathrm{m}^{2} / \mathrm{g}\right)\end{array}$ & $\begin{array}{c}V_{\mathrm{P}} \\
\left(\mathrm{cm}^{3} / \mathrm{g}\right)\end{array}$ & & \multicolumn{3}{c}{ Doped with PVA + La } \\
\hline 450 & 3.1 & 349 & 0.30 & & $\begin{array}{c}S_{\mathrm{BET}} \\
\left(\mathrm{m}^{2} / \mathrm{g}\right)\end{array}$ & $\begin{array}{c}V_{\mathrm{P}} \\
\left(\mathrm{cm}^{3} / \mathrm{g}\right)\end{array}$ \\
900 & 7.8 & 45.5 & 0.25 & & 7.1 & 324 & 0.28 \\
1000 & 12.6 & 43.7 & 0.17 & & 4.2 & 79 & 0.25 \\
1100 & 109 & 6.5 & $0.17^{*}$ & & 17.2 & 30 & 0.23 \\
1200 & 132 & 1.0 & $0.17^{*}$ & 106 & 8.0 & 0.18 \\
\hline
\end{tabular}




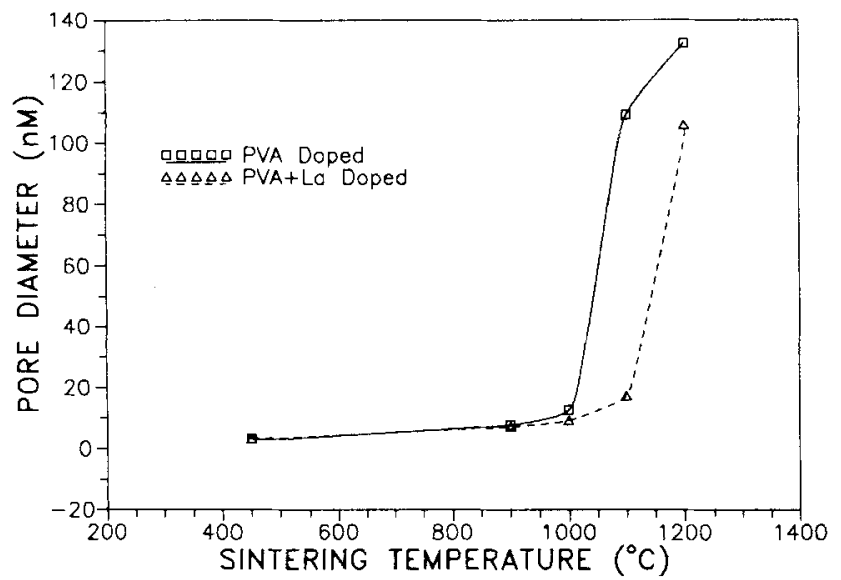

Fig. 4. Comparison of effects of sintering temperature (for $30 \mathrm{~h}$ ) on the average pore size between La-doped top layer and nonLa-doped top layer.

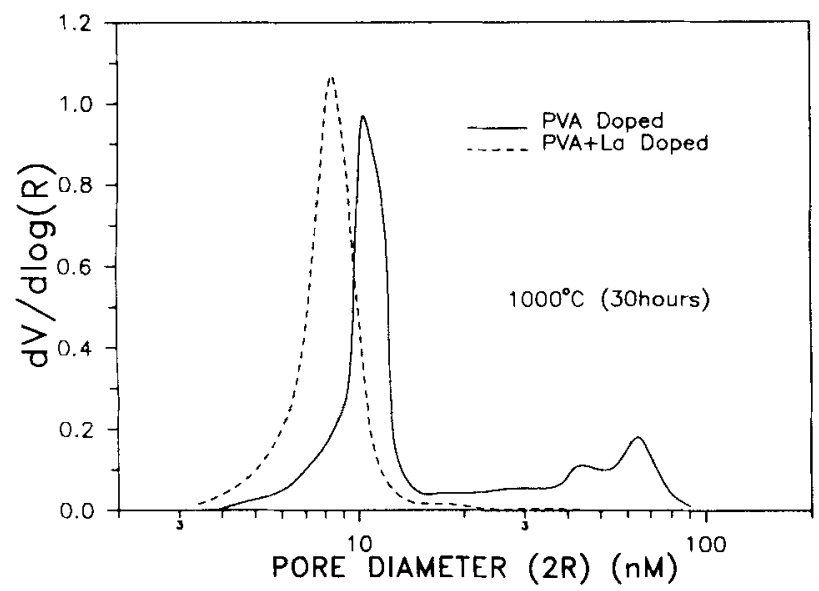

Fig. 5. Pore size distribution of the La-doped top layer and nonLa-doped top layer after sintering at $1000^{\circ} \mathrm{C}$ for $30 \mathrm{~h}$.

by the direct doping method (see the Experimental Procedure section). It was found in the previous study ${ }^{12}$ that for the unsupported alumina top layers the values of $R$ are the same for these two doping methods because of the same La content in the unsupported top layers prepared by these two methods. These results seem to suggest that the direct doping method is superior to the wet-impregnation method for preparing the thermally stable membrane composite.

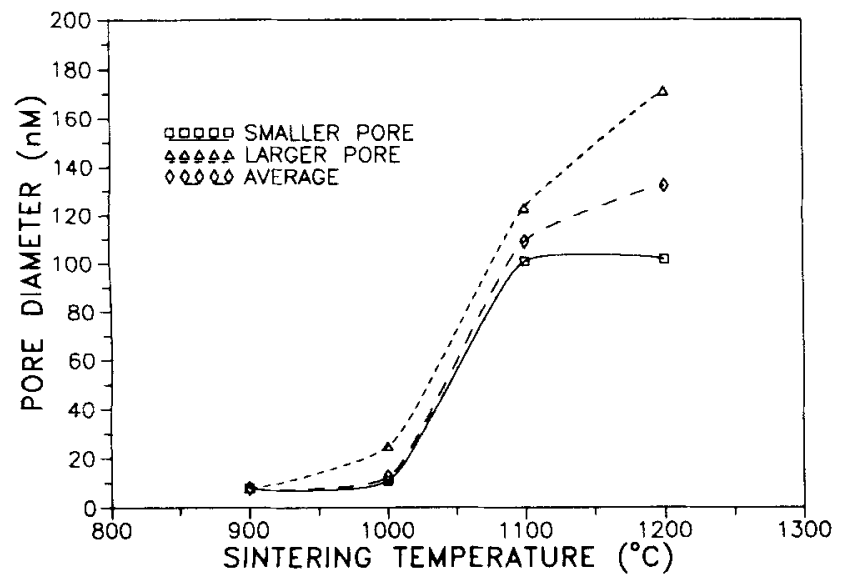

Fig. 6. Temperature effects on the growth of the two groups of pores for the non-La-doped top layer (with PVA); sintering time is $30 \mathrm{~h}$.

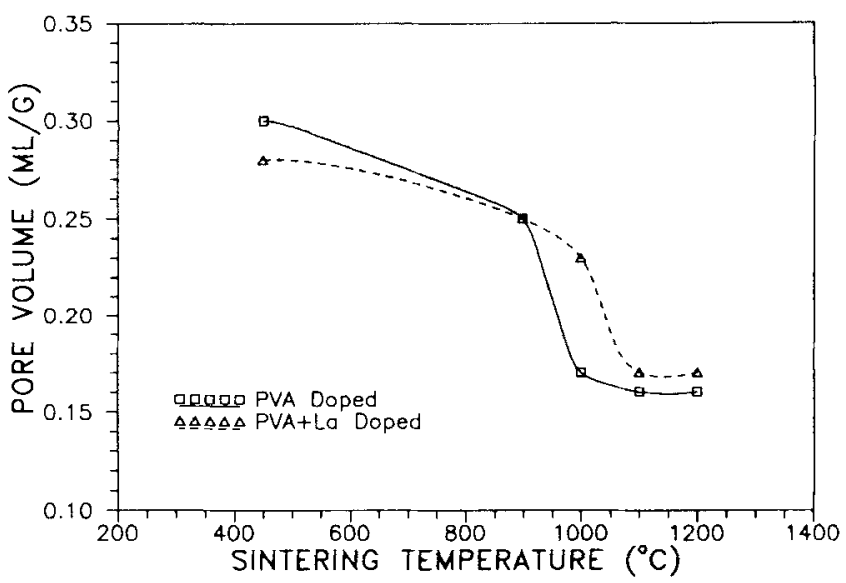

Fig. 7. Effects of sintering temperature on the pore volume of the two alumina top layers; sintering time is $30 \mathrm{~h}$.

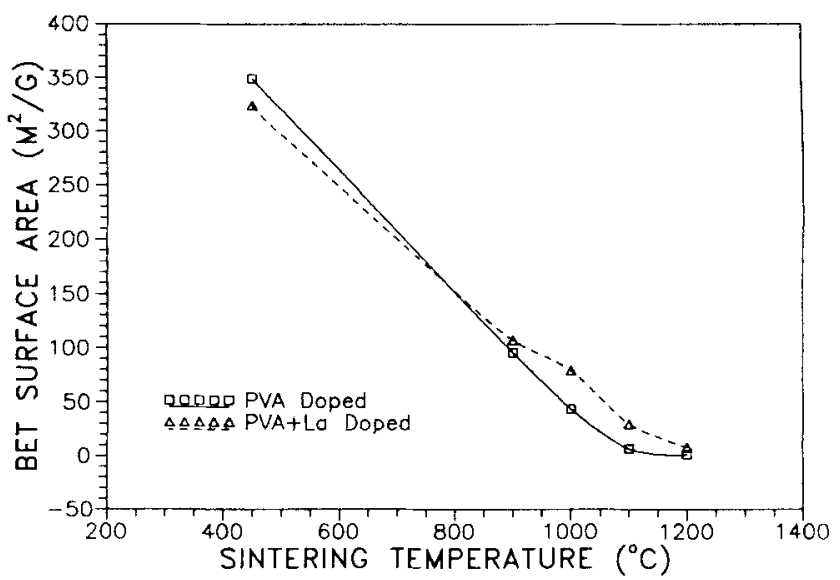

Fig. 8. Effects of sintering temperature on the surface area of the two alumina top layers; sintering time is $30 \mathrm{~h}$.

\section{Conclusions}

(1) A composite alumina membrane consisting of a top layer with improved thermal stability was prepared by the sol-gel method using a La-doped boehmite sol. The addition of PVA and proper control of the aging time and boehmite concentration are essential to the formation of a crack-free supported top layer of this improved membrane. After sintering at $1100^{\circ} \mathrm{C}$ for $30 \mathrm{~h}$, the pore diameter of the La-doped top layer is smaller than $20 \mathrm{~nm}$. In contrast, the pore diameter of the common alumina top layer (without doping with La) is about $110 \mathrm{~nm}$.

(2) The alumina membrane top layer prepared from boehmite sol with PVA (mol wt $=72000$ ) as the additive (the common alumina membrane) exhibits bimodal pore distribution after sintering at temperatures higher than $900^{\circ} \mathrm{C}$. The La-doped top layer (also with PVA) however retains the monopore distribution after sintering at temperatures up to $1200^{\circ} \mathrm{C}$.

(3) The pore size data for the supported top layers measured by the gas permeability method and the unsupported top layers of the same type measured by the porosimetry method were found to agree well with each other.

\section{References}

${ }^{1}$ A. J. Burggraaf and K. Keizer; Ch. 2 in Inorganic Membranes: Synthesis, Characterization and Properties. Edited by R. Bhave. Van Nostrand Reinhold, New York, in press.

${ }^{2}$ K. Keizer and A. J. Burggraaf, "Porous Ceramic Materials in Membrane Applications," Sci. Ceram., 14, 83-93 (1988).

${ }^{3}$ A. Larbot, J. P. Fabre, C. Guizard, and L. Cot, "Inorganic Membranes 
224

Journal of the American Ceramic Society - Lin and Burggraaf

Vol. 74 , No. 1

Obtained by Sol-Gel Techniques,"J. Memb. Sci., 39, 203-12 (1988).

${ }^{4}$ R. J. R. Uhlhorn, K. Keizer, and A. J. Burggraaf, "Formation of and Gas Transport Mechanism in Ceramic Membrane"; pp. 239-58 in Advances in Reverse Osmosis and Ultrafiltration. Edited by T. Matsuura. American Chemical Society, Washington, D.C., 1989.

${ }^{5}$ A. Larbot, J. P. Fabre, C. Guizard, and L. Cot, "New Inorganic Ultrafilration Membranes: Titania and Zirconia Membranes," J. Am. Ceram. Soc., 72 [2] 257-61 (1989).

${ }^{6}$ A. F. M. Leenaars, K. Keizer, and A. J. Burggraaf, "The Preparation and Characterization of Alumina Membranes with Ultrafine Pores," $J$. Mater. Sci., 19, 1077-88 (1984).

${ }^{7}$ A. J. Burggraaf, K. Keizer, and B. A. van Tassel, "Ceramic Nanostruc. tore Materials, Membranes and Composite Layers," Solid State Ionics, 32/33, $771-81$ (1989).

${ }^{8}$ A. Larbot, J. A. Alary, J. P. Fabre, C. Guizard, and L. Cot, "Microporous Layers from Sol-Gel Techniques,” Mater. Res. Soc. Symp. Proc., 73, 659-64 (1986).

${ }_{9}^{9}$ A. Larbot, J. A. Alary, C. Guizard, J. P. Fabre, N. Idrissi, and L. Cot, "Thin Layers of Ceramics from Sol-Gel Process (Organic Membranes) for Liquid Separation"; pp. 2259-63 in High Tech Ceramics, Material Science Monograph. Edited by P. Vincenzini. Elsevier, Amsterdam, Netherlands, 1987.

${ }^{10}$ H. M. van Ven, J. P. M. Top, R. A. Terpstra, A. J. G. Angel, and H. J. Veringa, "The Calcination and Thermal Stability of Ceramic $\mathrm{Al}_{2} \mathrm{O}_{3} \mathrm{Mem}$. brants for Gas Separation"; pp. 3585-89 in Euro-Ceramics, Vol. 3, Engineer- ing Ceramics. Elsevier, Amsterdam, Netherlands, 1989.

${ }^{11}$ Y. S. Lin, L. G. J. de Heart, K. J. de Vries, and A. J. Burggraaf, "Modifycation of Ceramic Membranes by CVD and EVD for Gas Separation, Canalysis and SOFC Application"; pp. 3590-95 in Euro-Ceramics, Vol. 3, Engneering Ceramics. Elsevier, Amsterdam, Netherlands, 1989.

${ }^{12}$ Y. S. Lin, K. J. de Vries, and A. J. Burggraaf, "Thermal Stability and Its Improvement of Alumina Membrane Top-Layers Prepared by Sol-Gel Method," J. Mater. Sci., in press.

${ }^{13}$ R. J. van Vuren, B.C. Bonekamp, K. Keizer, R. J. R. Uhthorn, H. J. Veringa, and A.J. Burggraaf, "Formation of Ceramic Alumina Membranes for Gas Separation"; pp. $2235-45$ in High Tech Ceramics. Edited by P. Vincenzini. Elsevier, Amsterdam, Netherlands, 1987.

${ }^{14}$ K. Keizer, R. J. R. Uhlhorn, R. J. van Vuren, and A. J. Burggraaf, "Gas Separation Mechanisms in Microporous Modified $\gamma-\mathrm{Al}_{2} \mathrm{O}_{3}$ Membranes," J. Membr. Sci., 39, 285-300 (1988).

${ }^{15}$ W. S. Bey and K. A. Krieger, "The Surface Area and Catalytic Activity of Aluminum Oxide," J. Am. Chem. Soc., 71, 3637-41 (1949).

${ }^{16}$ R. M. Levy and D. J. Bauer, "The Effects of Foreign Ions on the Stability of Activated Alumina," J. Catal., 9, 76-86 (1967).

${ }^{17}$ E. M. Ezzo, T. Einabarawy, and A. M. Youssef, "Studies on the Mixed Oxide Catalyst: Alumina Oxide-Chromium (III) Oxide," Surf. Technol., 9, $111-18$ (1979).

${ }^{18}$ H. Schaper and L. L. van Reijen, "The Influence of Dopes on the Stability of Gamma Alumina Catalyst Support," Mater. Sci. Monogr., 14, 173-76 (1982). 